\title{
La irrupción de los conversos portugueses en el comercio de exportación de lanas de la Corona de Castilla en el tránsito del siglo XVI al XVII
}

\author{
Máximo Diago Hernando \\ Instituto de Historia, CCHS - CSIC ${ }^{*}$
}

\begin{abstract}
Los judeoconversos portugueses, muchos de ellos descendientes de judíos castellanos expulsados en 1492, desempeñaron un destacado papel en el comercio exterior de la Corona de Castilla durante el siglo XVII. Entre sus múltiples actividades estuvo la de exportación de lana fina castellana a Francia, los Países Bajos y otros territorios europeos. En el presente trabajo el autor contribuye a la reconstrucción de la primera fase de participación de estos mercaderes en dicho negocio, a partir de las últimas décadas del siglo XVI, tras el abandono de la actividad por los mercaderes burgaleses. $\mathrm{Y}$ lo hace desde una perspectiva geográfica limitada, centrando el análisis en una región en concreto, la de la Tierra de Soria y su entorno.
\end{abstract}

Palabras clave: Castilla; Portugal; Edad Moderna; historia económica; comercio lanero; judeoconversos; mercaderes.

The Inrush of Portuguese Conversos in the Wool Export Trade from the Crown of Castile AT THE END OF THE $16^{\mathrm{TH}}$ AND THE BEGINNING OF THE $17^{\mathrm{TH}}$ CENTURY.-Portuguese Conversos, many of them descendants of the Castilian Jews that were expelled in 1492, played a very important role in the export trade of the Crown of Castile during the $17^{\text {th }}$ century. Among their multiple activities, the export of Castilian wool to France, the Low Countries and other European regions, was a prominent one. In this article the author contributes to the reconstruction of the first phase of the process of involvement of these merchants in this business, from the last decades of the $16^{\text {th }}$ century onwards, after the merchants of Burgos abandoned it. He adopts a limited geographical perspective, because he circumscribes his analysis to a single region, that of Soria and its surroundings.

Keywords: Castile; Portugal; Modern Period; Economic History; Wool Trade; Conversos; Merchants.

Han sido muchos los historiadores que han llamado la atención sobre el destacado papel que los hombres de negocios portugueses de origen judeoconverso desempeñaron en la economía de la Corona de Castilla durante

\footnotetext{
*maximo.diago@cchs.csic.es
} 
el siglo XVII, aunque ciertamente la faceta de su actividad a la que más atención se ha prestado ha sido la financiera. Muchas páginas se han dedicado a analizar y poner de relieve la intensa actividad desplegada por individuos pertenecientes a esta «nación» en la contratación de «asientos» con la Real Hacienda durante los reinados de Felipe IV y Carlos II, en especial a partir de mediados de la década de 1620, cuando, por iniciativa del Conde-Duque de Olivares, se les dio entrada en un negocio hasta entonces en gran medida controlado por los financieros genoveses ${ }^{1}$. También se ha llamado la atención, por supuesto, sobre la actividad desplegada por estos mismos portugueses como mercaderes ${ }^{2}$. Y, más en concreto se ha puesto el acento en algunos trabajos recientes en la demostración de la tesis de que se contaron entre los mayores contrabandistas del reino, que introducían en la Corona de Castilla grandes cantidades de mercancías que en virtud de los embargos decretados contra los holandeses en 1623 y los franceses en 1635 estaba prohibido introducir en los dominios de la Monarquía Hispánica, a no ser que se dispusiese de licencia para ello ${ }^{3}$.

No ha pasado desapercibido tampoco a los investigadores el hecho de que, entre las mercancías con las que negociaron los mercaderes portugueses de origen judeoconverso que operaron en Castilla durante el siglo XVII, ocupó un lugar muy destacado la lana fina de ganado trashumante. No obstante, el papel que estos mercaderes desempeñaron en el mercado lanero no ha sido valorado en toda su complejidad, puesto que la atención preferente de los investigadores se ha dirigido precisamente hacia las exportaciones de lanas realizadas por los grandes asentistas de origen portugués que estuvieron al servicio de la Real Hacienda durante los reinados de Felipe IV y Carlos II, las cuales se han explicado como consecuencia de la necesidad que tenían estos grandes financieros de disponer de plata en el exterior, para realizar allí las provisiones concertadas con la

\footnotetext{
${ }^{1}$ Entre otras muchas obras cabe destacar James C. BoyaJIAn, Portuguese Bankers at the Court of Spain. 1626-1650 (New Brunswick 1983); Julio CARO BAROJA, La sociedad criptojudía en la Corte de Felipe IV (Madrid 1963); Carlos Álvarez Nogal, El crédito de la Monarquía Hispánica durante el reinado de Felipe IV (Valladolid 1997); Antonio Dominguez Ortiz, Política y Hacienda de Felipe IV (Madrid 1960); Carmen SAnZ Ayán, Los banqueros de Carlos II (Valladolid 1988).

${ }^{2}$ Nicolás BRoEns, Monarquía y capital mercantil: Felipe IV y las redes comerciales portuguesas (1627-1635) (Madrid 1989); Bernardo LóPEz Belinchón, Honra, Libertad y Hacienda (Hombres de negocios y judíos sefardíes) (Madrid 2001).

${ }^{3}$ Bernardo LÓPEz BeLINCHÓN, «Sacar la sustancia del reino. Comercio, contrabando y conversos portugueses, 1621-1640», Hispania 209 (2001), págs. 1017-1050. Sobre los efectos que los sucesivos embargos y represalias decretados por la monarquía española a lo largo del siglo XVII tuvieron sobre el comercio, vid. Ángel Alloza Aparicio, Europa en el mercado español. Mercaderes, represalias y contrabando en el siglo XVII (Valladolid 2006).
} 
Monarquía, dado que ellos compraban la lana en Castilla con moneda de vellón y la vendían en el extranjero exigiendo su pago en plata ${ }^{4}$.

Lo cierto, no obstante, es que el número de individuos de origen judeoconverso portugués que participaron activamente en el comercio de lanas en Castilla desde las últimas décadas del siglo XVI, y durante gran parte del siglo XVII, fue elevadísimo y, entre ellos, los grandes asentistas representan una exigua minoría, que además está en gran medida ausente en la primera fase de participación de este grupo en el mercado lanero, la que abarca los reinados de Felipe II y Felipe III. Hubo, pues, muchos portugueses que participaron en el comercio de lanas por motivos que nada tienen que ver con el objetivo de disponer de plata en el extranjero para cumplir con los compromisos contraídos en los asientos concertados con la Real Hacienda. Y sobre ellos apenas encontramos referencias en la bibliografía especializada en la historia económica de la Castilla del siglo XVII, que, por el contrario, en ocasiones contiene afirmaciones que no valoran adecuadamente el papel que desempeñaron en esta actividad, de importancia clave para el reino en esta época. Así, por ejemplo, tenemos que un historiador de tan reconocido prestigio como Jonathan Israel sostiene que en el período entre 1609 y 1621 los conversos portugueses que habían emigrado a Castilla apenas consiguieron controlar una pequeña parte del mercado lanero y sólo más adelante, en las décadas de 1640 y 1650, alcanzaron en él un mayor protagonismo, proporcionando al reino de Castilla algunos de sus principales tratantes, tales como Sebastián Cortizos, Fernando Montesinos y Francisco Duarte Méndez, es decir, personajes que fueron al mismo tiempo destacados asentistas ${ }^{5}$. Y, por su parte, Carla y William Philipps, en su panorámica general sobre la evolución del comercio de exportación de lanas de la Corona de Castilla entre los siglos XV y XIX, prácticamente ignoran el papel que en el mismo desempeñaron los mercaderes de origen portugués, limitándose a indicar que en el siglo XVII los extranjeros más prominentes en el comercio de exportación de lanas a través de los puer-

${ }^{4}$ Una primera formulación de esta tesis en Ángel GarCía SANZ, «Crédito, comercio y exportación de lana merina», en Antonio M. Bernal (Ed.), Dinero, moneda y crédito en la monarquía hispánica (Madrid 2000), págs. 495-510. Más adelante fue asumida por Enrique LLopIs Agelán, «La pila de lana de la cabaña trashumante del monasterio de Guadalupe: dimensión, venta y estrategia comercial», en Agustín GonZÁLEZ ENCISO (ed.), El negocio de la lana en España (1650-1830) (Pamplona 2001), págs. 48 y ss.; y Carmen SANZ AYÁn, «Las redes financieras franco-holandesas y la lana en el tránsito del siglo XVII al XVIII», en GonZÁlez EnCiso (ed.), El negocio de la lana, págs. 82 y ss.

${ }^{5}$ Jonathan IsRael, Empires and Entrepots. The Dutch, the Spanish Monarchy and the Jews, 1585-1713 (London 1990), págs. 395-396. 
tos del norte fueron los franceses, seguidos de los naturales de Gran Bretaña, Portugal y Flandes, sin hacer más precisiones ${ }^{6}$.

Existe, por lo tanto, a nuestro juicio, un importante vacío historiográfico en lo que se refiere al conocimiento de los cambios que en la composición de los grupos que controlaron el comercio exterior de la Corona de Castilla tuvieron lugar tras la desaparición de las grandes casas de negocios burgalesas en las décadas finales del reinado de Felipe II. El abandono de los negocios mercantiles, y más en particular del de exportación de lanas finas a los Países Bajos y Francia, por la práctica totalidad de los vecinos de Burgos, que habían desempeñado un papel hegemónico en el mismo durante el siglo XV y la primera mitad del siglo $\mathrm{XVI}^{7}$, dejó abierto un importante hueco en el ámbito del comercio exterior de la Corona de Castilla que, por falta de investigaciones, no sabemos muy bien cómo fue progresivamente cubierto en las últimas décadas del siglo XVI y en las primeras del siglo XVII. De ahí que un estudio orientado a profundizar en la reconstrucción del proceso de irrupción de los judeoconversos portugueses en el mercado lanero de la Corona de Castilla ofrezca un indiscutible interés, porque precisamente éste fue uno de los grupos que mayor protagonismo llegó a alcanzar en el comercio de exportación de lanas, en especial a través de los puertos del Cantábrico, por mar, y a través de Navarra, por tierra, durante el siglo XVII.

En el estado actual de las investigaciones, y dado que la documentación disponible para el análisis de esta problemática es muy abundante, se encuentra bastante dispersa, y es de difícil manejo por falta de instrumentos descriptivos en los archivos, resulta imposible de momento realizar un estudio en profundidad de este proceso desde una perspectiva global. Se impone por el contrario la necesidad de adoptar perspectivas parciales, que permitan un aprovechamiento más intensivo de la documentación. Y una de estas perspectivas es la que se limita a tomar en consideración un espacio geográfico muy limitado, como es la Tierra de Soria y su entorno serrano, que ofrece el incentivo de haber constituido entre los siglos XV y XIX una de las principales regiones productoras de lanas finas para la exportación de la Corona de Castilla. En el comercio lanero de esta región alcanzaron durante los siglos XV y XVI un indiscutido protagonismo las firmas mercantiles burgalesas, que, no obstante, a partir de la década de 1580

${ }^{6}$ Carla Rahn Phillips y William D. Phillips Jr., Spain's Golden Fleece. Wool Production and the Wool Trade from the Middle Ages to the Nineteenth Century (Baltimore 1997), págs. 184-185.

${ }^{7}$ Vid. Hilario CAsado Alonso, «El comercio internacional burgalés en los siglos XV y XVI», en Actas del V Centenario del Consulado de Burgos (Burgos 1994), vol. I, págs. 175-247; y Manuel Basas Fernández, El Consulado de Burgos en el siglo XVI (Madrid 1963). De este mismo autor interesan varios artículos publicados en el Boletín de la Institución Fernán González. 
abandonaron en su mayoría el negocio, con la consecuencia de que a principios del siglo XVII sólo encontramos operando con lanas en la región soriana a unos pocos vecinos de la ciudad del Arlanzón, que, por lo demás, ocupaban una posición claramente secundaria en el mercado.

Hasta ahora apenas se ha prestado atención por los investigadores al análisis de la evolución del comercio lanero en la región soriana tras el período de esplendor de las exportaciones a Flandes, canalizadas de forma preferente, aunque no exclusiva, por las grandes casas mercantiles burgalesas, que podemos dar ya por concluido en la década de 1570, cuando se produjo una primera caída importante de las exportaciones y de los precios de la lana. Esta primera gran crisis del comercio lanero soriano, que tuvo un importante efecto sobre las explotaciones ganaderas trashumantes de la región, constituye un complejo proceso con múltiples ramificaciones, y que cabe estudiar desde numerosas perspectivas. El abandono del negocio de la exportación de lanas por los mercaderes burgaleses, y su sustitución por mercaderes de otras procedencias, representa sólo una entre las muchas caras de este poliédrico fenómeno. Pero no cabe duda de que la clarificación de esta cuestión puede contribuir a la mejor comprensión del proceso en su conjunto. Y lamentablemente hasta ahora es muy poco lo que se ha avanzado en este terreno, pues en las publicaciones disponibles apenas se dice nada sobre quiénes se hicieron con el control de las exportaciones de las lanas sorianas a partir de los últimos años del reinado de Felipe II.

Por ello hemos juzgado de interés escoger la región soriana para iniciar nuestra tarea de indagación sobre la irrupción de los mercaderes portugueses en el comercio lanero de la Corona de Castilla, del que se mantuvieron apartados durante la mayor parte del siglo XVI, pero en el que, por contraste, alcanzaron un decisivo protagonismo en el siguiente siglo.

$\mathrm{Al}$ acometer este trabajo pretendemos por consiguiente efectuar una contribución a la historia económica de la Castilla moderna, profundizando en el análisis de la evolución de un sector clave de su comercio exterior. Pero, al mismo tiempo, es nuestra intención contribuir también a la historia social, iluminando una importante faceta de la actividad de la minoría judeoconversa en los territorios de la Monarquía de los Austrias. Los mercaderes de lanas de los que vamos a hablar aquí aparecen siempre identificados en los documentos como portugueses. Pero, según todos los indicios, eran en su práctica totalidad descendientes de judíos, por lo que muchos de ellos tuvieron problemas con la Inquisición, e incluso algunos, cuando se instalaron en lugares donde se observaba la tolerancia religiosa, terminaron por practicar abiertamente la religión judía. Teniendo en cuenta que muchos judíos castellanos se instalaron en Portugal tras 
la publicación del decreto de expulsión por los Reyes Católicos en 1492, no consideramos improbable que una parte importante de los portugueses que se instalaron en Castilla, todos ellos ya formalmente convertidos al cristianismo, durante el reinado de Felipe II y, en número aún mayor, durante el de Felipe III, tuviesen en sus venas sangre de aquellos judíos desterrados. Por ello al hablar de los portugueses como de un grupo de extranjeros habría que tomar muchas cautelas. Pero, ante todo, lo que nos interesa aquí resaltar es que el grupo de mercaderes que vamos a tomar en consideración en el presente trabajo, más que por el hecho de ser súbditos del rey de Portugal, que a partir de 1580 fue la misma persona que ocupaba el trono castellano, se definían por su común condición de descendientes de judíos, que resultaba determinante para muchos aspectos de su modo de vida, entre otras razones porque seguían observando muchas de las costumbres de sus antepasados.

No es nuestra intención profundizar en este trabajo en el estudio de las condiciones de vida y formas de sociabilidad de los mercaderes de los que vamos a tratar. Por el contrario nos centraremos exclusivamente en dar cuenta del papel que desempeñaron en el mercado lanero. Pero sin duda éste también se explica en gran medida como consecuencia de la adopción por dichos mercaderes de unas pautas de vida y de comportamiento que se explican por razón de su pertenencia a la minoría judeoconversa. Y así tendremos ocasión de irlo comprobando en las siguientes páginas.

\section{LA INCORPORACIÓN DE LOS MERCADERES DE ORIGEN PORTUGUÉS AL MERCADO LANERO DE LA REGIÓN SORIANA EN LOS AÑOS FINALES DEL SIGLO XVI}

Los individuos de origen portugués comienzan a hacer acto de presencia de forma progresiva en la región soriana en el transcurso de la segunda mitad del siglo XVI, pero su irrupción en el comercio de lanas no tuvo lugar hasta los años finales de dicho siglo, a juzgar por las informaciones hasta ahora disponibles. Los primeros contactos de la sociedad soriana con los mercaderes originarios de Portugal tuvieron por escenario las ferias de Medina del Campo, en las que la presencia portuguesa ya venía siendo un fenómeno importante desde el siglo $\mathrm{XV}^{8}$, que, por lo demás, fue adquiriendo cada vez mayor relevancia en el transcurso del siglo XVI, a juzgar por las noticias encontradas en los protocolos

\footnotetext{
${ }^{8}$ Vid. $\mathrm{M}^{\mathrm{a}}$. Isabel Del Val VAldivieso, «Mercaderes portugueses en Medina del Campo (siglo XV)», en Actas das II Jornadas Luso-Espanholas de História Medieval (Porto 1987), vol. II, págs. 591-608.
} 
notariales de esta villa vallisoletana, que, desafortunadamente, todavía no han sido objeto de un análisis sistemático desde esta perspectiva ${ }^{9}$.

En Medina del Campo, por ejemplo, mercaderes sorianos concertaron la venta a mercaderes portugueses de productos textiles fabricados en la región soriana, como nos testimonia el contrato concertado en 1549 por el mercader pañero Mateo Sanz, quien vendió a Pedro Váez y Manuel Hernández 27 piezas de tejidos a 7.000 mrs. cada una ${ }^{10}$. Y, en contrapartida, los sorianos adquirieron en dicha plaza de sus colegas portugueses productos colorantes destinados a la manufactura pañera, como el añil. Pero pronto estos últimos pasaron a trasladarse en persona a la región soriana para llevar adelante sus negocios, aunque sin abandonar Medina del Campo como su principal centro de operaciones en Castilla. Así lo prueba el contrato firmado en Soria el 19 de marzo de 1572 por Juan de Fonseca Ferraz, mercader originario de Trancoso, con el soriano Antón de Santa Cruz, empresario fabricante de paños. En él este último se obligó a poner a disposición del portugués en Medina del Campo ocho paños palmillas dieciochenos morados y verdes de 26 varas cada uno, que habían de ser examinados por dos vecinos de Soria vinculados con el negocio pañero para que certificasen que no presentaban ningún defecto. Y, una vez superado el examen, se transportarían a Medina del Campo a costa del comprador, quien los había de pagar a razón de 26,5 ducados por cada uno de los paños morados, y 22 ducados por cada uno de los verdes ${ }^{11}$.

Los mercaderes portugueses a los que encontramos en la región soriana durante el reinado de Felipe II desarrollaron una actividad muy diversificada, negociando con una amplia gama de productos, entre los que, no obstante, en un primer momento no figuró la lana, o, al menos, no en un lugar destacado. Por otra parte, aunque el contrato que acabamos de mencionar nos los muestra en su faceta de compradores de mercancías, en esta primera fase su papel principal fue el de abastecedores de productos destinados a satisfacer la demanda local. Así, además de proveer a la manufactura pañera soriana de algunos productos colorantes, como el añil, y de otros como el hilo de cardas, que nos consta que les

${ }^{9}$ Referencias someras a esta cuestión en Falah H. A. AL-Hussern, «El comercio de los géneros textiles: seda, paños y lienzos», en Historia de Medina del Campo y su Tierra. Vol. II. Auge de las Ferias. Decadencia de Medina (Valladolid 1986), págs. 61 y ss. Afirma este autor que en el siglo XVI la «nación» portuguesa llegó a ser preeminente en Medina del Campo.

${ }^{10}$ Da noticia del contrato, conservado en los protocolos notariales de Medina del Campo, ALHussein, «El comercio de los géneros textiles», pág. 61.

${ }^{11}$ Archivo Histórico Provincial de Soria, Protocolos Notariales [en adelante, AHPS, PN], 79178, Soria, 19-III-1572. 
fueron comprados por fabricantes pañeros de la comarca serrana de Yanguas ${ }^{12}$, vendieron gran cantidad de lienzos, adquiridos de ellos a crédito por mercaderes sorianos $^{13}$. Y, entre la amplia gama de productos por ellos ofertados estuvieron también presentes las medicinas y las drogas, adquiridas por boticarios de muy diversos puntos de la geografía soriana ${ }^{14}$.

En un primer momento los mercaderes portugueses que realizaron negocios con sorianos fueron individuos que permanecían avecindados en ciudades de Portugal, pero que realizaban frecuentes y prolongados viajes de negocios a Castilla, para comprar y vender todo género de mercancías. Con el transcurso del tiempo, y conforme nos acercamos al final del reinado de Felipe II, fue resultando cada vez más frecuente, sin embargo, que hubiesen pasado a fijar su residencia en ciudades de la Corona de Castilla, o del sudoeste francés. Algunos, incluso, se avecindaron en la propia ciudad de Soria, donde durante el reinado de Felipe II se constituyó una pequeña comunidad de mercaderes portugueses, probablemente de origen judeoconverso, aunque no se dispone de pruebas contundentes que lo confirmen, la cual proporcionó a esta ciudad a varios de sus más dinámicos hombres de negocios a todo lo largo del siglo XVII, con notorio protagonismo en el comercio lanero, como propietarios y gestores de lavaderos de lanas, en el trato con cueros y en la manufactura pañera.

La presencia de mercaderes de origen portugués, pero emigrados a Castilla o al sur de Francia, se fue, pues, intensificando de forma apreciable en las tierras de Soria en las dos últimas décadas del reinado de Felipe II, tras recaer en este monarca la sucesión al trono de Portugal como consecuencia de la prematura muerte de su sobrino el rey Don Sebastián en su desafortunada campaña africana. En un primer momento, sin embargo, estos mercaderes se mantuvieron al margen del gran comercio lanero, dedicándose a negociar con otras mercancías como los lienzos, los paños, los colorantes, o las especias, aunque pronto los más emprendedores de entre ellos advirtieron las posibilidades de rápido enriquecimiento que ofrecía el negocio de la exportación de lanas finas a las regiones pañeras de la Europa ultrapirenaica, y comenzaron a realizar incursiones en el mismo.

\footnotetext{
${ }^{12}$ Noticia de la compra en 1586 de madejas de hilo de cardas por un matrimonio de Yanguas a Pedro Rodríguez, mercader de origen portugués avecindado en la villa riojana de Haro, en AHPS, PN, 2758-4711.

${ }^{13}$ En Soria, 17-VII-1589, Pedro de Aguilar se obligó a pagar a Alonso Gómez Enríquez, mercader originario de Trancoso, 200 reales para el próximo día de Todos los Santos por seis piezas de lienzos que le había comprado. AHPS, PN, 195-398-469.

${ }^{14}$ En Soria, 5-I-1585, Jerónimo de Melian, boticario vecino de Calatañazor, se obligó a pagar en dos plazos a Luis Núñez, mercader portugués residente en Burdeos, 251 reales que le adeudaba de resto del valor de medicinas y drogas que le había comprado. AHPS, PN, 83-189-208.
} 
Las trayectorias de algunos de estos mercaderes, que gracias a la documentación inquisitorial podemos reconstruir con mayor detalle, pueden servirnos de ilustración para conocer cómo tuvo lugar el proceso. Así, cabe destacar como caso paradigmático el de Baltasar Méndez Trancoso, individuo descendiente de judíos, originario de esta ciudad portuguesa de la región de Tras-os-Montes, que fue cuna de otros muchos mercaderes que desarrollaron una intensa actividad mercantil en la Corona de Castilla en las últimas décadas del siglo Xvi y durante el siglo XVII ${ }^{15}$. Gracias a una detallada declaración que realizó ante un tribunal inquisitorial $^{16}$, sabemos que tuvo una ajetreada existencia, desde que con apenas 10 años abandonó la casa de sus padres en Trancoso para ir a vivir con un hermano que tenía en Lisboa, el cual le puso a trabajar como paje con una hidalga que era criada de la camarera de la infanta doña María. Tras permanecer en este puesto durante unos cuatro años fue llevado luego por sus hermanos a Castilla, a un lugar del señorío del marqués de Cañete, cercano a Cuenca, llamado La Parrilla, donde permaneció durante cuatro años haciendo paños y sirviendo como paje a una cuñada del marqués de Cañete. Poco después se inició su carrera como mercader, tras haberle entregado un hermano suyo en Lisboa 300 cruzados en dinero a fin de que con ellos se comenzase a ejercitar en el trato mercantil, yendo en compañía de un corredor que se lo había de enseñar. Compró y vendió todo tipo de mercancías, desde paños hasta plomo, pasando por añinos negros para sombreros, algodón, añil, pastel, almizcle, pimienta, clavo, canela, o ropa de India y Brasil. Habitualmente adquiría una partida de alguna de estas mercancías en un lugar y la llevaba a vender a otro, trocándola por mercancías de otro género, que de nuevo llevaba a vender a un tercer lugar diferente. Como consecuencia en estos años, en que todavía permanecía soltero, estuvo moviéndose continuamente entre ciudades del reino de Portugal y lugares muy diversos del reino de Castilla, como Medina del Campo, Medina de Rioseco, Villoslada de Cameros, Alcalá de Henares, Priego, Cuenca, Palencia o Puente del Arzobispo, entre otras. Pronto dio además el salto al otro lado de los Pirineos, a raíz de llevar a vender a Bayona unas frazadas que había adquirido en Palencia, las cuales trocó por pastel que destinó a la región de Cuenca. Y fue con ocasión de esta estancia en la referida ciudad francesa cuando se produjo su primera toma de contacto con el negocio lanero, pues, según su propia confesión, a raíz de la misma «vio el trato de las lanas y quedó con ánimo de tratar en él, porque vio

${ }^{15}$ Más detalles sobre las comunidades judeoconversas del noroeste de Portugal, región de fuerte impronta rural en la época, de donde fueron originarios muchos hombres de negocios que operaron en Castilla durante el siglo XVII, tales como el célebre Fernando Montesinos, en LóPEZ BeLINCHÓn, Honra, Libertad, capítulo I.

${ }^{16}$ AHN, Inquisición, 62-5. 
que se ganaba mucho». Por ello poco tiempo después, habiendo llevado a vender desde Lisboa a la villa castellana de Puente del Arzobispo un cargamento de plomo, decidió invertir parte del dinero obtenido en la operación en la compra de 2.300 arrobas de lana, que lavó y ensacó in situ para a continuación hacerlas transportar en cabalgaduras hasta la ciudad de Vitoria, a poder de Martín de Aramayona, aduanero, a quien transmitió la orden de que se las encaminase hasta el puerto francés de San Juan de Luz. Hasta allí se trasladó el propio Baltasar Méndez Trancoso para hacerse cargo de la venta de las lanas, que llevó a efecto trocándolas por «lencerías de Navales, Ruanes y lencería cruda». La operación resultó de su entera satisfacción, pues «halló que en el dicho trato había ganado en aquella partida ciento por ciento». Y ello le animó a continuar con este negocio, del que hasta entonces se había mantenido totalmente apartado, de modo que «con la codicia del provecho, se fue a Soria, donde compró más de tres mil arrobas de lana de Don Diego de Medrano», caballero que en aquellos momentos era uno de los mayores propietarios de ganado trashumante de esta ciudad $^{17}$, las cuales de nuevo hizo conducir hasta San Juan de Luz, a donde se trasladó en persona para hacerse cargo de su venta, que también en esta ocasión realizó con provecho y amplio margen de ganancia. Animado por los buenos resultados obtenidos en estas operaciones decidió incrementar sus inversiones en este negocio, de modo que, tras una breve estancia de un mes en su ciudad natal de Trancoso, a donde se trasladó a visitar a su mujer, volvió de nuevo a Soria para adquirir lanas, haciéndose en esta ocasión otra vez con una partida de Don Diego de Medrano, a la que sumó otra de 1.500 arrobas de un primo suyo vecino de Ágreda, las cuales de nuevo llevó a vender a San Juan de Luz. Poco después constituyó una compañía mercantil con otros dos mercaderes portugueses, Melchor Gómez y Diego Ferreira, que estaban establecidos en Vitoria, por cuenta de la cual se realizaron varias operaciones de compra de lanas en la región soriana en los años 1595 y $1596^{18}$, y se tomó a renta un lavadero para beneficiarlas a Juan García de Tardajos, destacado hombre de negocios de la ciudad de Soria, de probable origen judeoconverso ${ }^{19}$. Y, además, también se efectuaron diversas

${ }^{17}$ Vid. Máximo Diago Hernando, «Los caballeros ganaderos de Soria y su Tierra durante los siglos XVI y XVII. Contribución al estudio del grupo de los grandes señores de ganados mesteños», Celtiberia 97 (2003), págs. 127-172.

${ }^{18}$ En 8-VII-1596 Melchor Gómez y Baltasar Méndez, estando ambos en Soria, se dieron mutuamente poderes para todos sus negocios. AHPS, PN, 202-418-30. Noticia sobre la compra por estos dos a Bernardino de las Heras de las lanas del esquileo de 1595 en AHPS, PN, 202-41686. Sobre la compra al mismo de las lanas del esquileo de 1596, AHPS, PN, 203-420-255.

${ }^{19}$ Sobre este personaje vid. Máximo Diago Hernando, «Los hombres de negocios en la ciudad de Soria durante el siglo XVI», Hispania 205 (2000), págs. 479-514. Noticia del arrendamiento del 
operaciones de venta a crédito de una amplia gama de productos, desde lienzos de Flandes ${ }^{20}$, hasta corchetes, alfileres, agujetas y otros productos de mercería ${ }^{21}$. Según la declaración prestada por Baltasar Méndez Trancoso ante los inquisidores, en aquel momento decidió fijar su residencia en Castilla, para lo cual se trajo a su mujer desde Trancoso, avecindándose en la villa de Madrid, donde entonces tenía fijada su sede la Corte. Los documentos notariales sorianos atestiguan que en 1597 ya era vecino de la villa del Manzanares, desde donde continuó realizando tratos con lanas en Soria, ahora en compañía con otro portugués llamado Pedro Álvarez, vecino a su vez de Madrid ${ }^{22}$. Continuó en relación, no obstante, con sus compañeros de Vitoria, Melchor Gómez y Diego Ferreira, que le enviaban a la Corte mercancías procedentes de San Juan de Luz, a donde tal vez se había trasladado a residir alguno de ellos, mientras que él por su parte les enviaba lanas para que las vendiesen en la mencionada ciudad francesa. En Madrid permaneció durante unos tres años, dedicado a estos negocios, y allí dio a luz su mujer a su hija Leonor, que fue bautizada en la iglesia de San Sebastián. Al cabo de los tres años, decidió, no obstante, trasladarse a residir a San Juan de Luz, a donde al poco le siguieron su hija y su mujer, que, nada más llegar, dio a luz a un varón, Juan Méndez Pastor ${ }^{23}$. Y allí continuó dedicado al trato en lanas y en «otras muchas suertes de mercancías», al menos hasta el año 1620, fecha en que prestó declaración ante los inquisidores, siendo todavía vecino de la referida ciudad francesa.

lavadero en AHPS, PN, 205-422-351. Un contrato de un operario para trabajar en el lavadero a partir de mediados de junio de 1596, realizado por Melchor Gómez, estante entonces en Soria, en AHPS, PN, 202-416-117, Soria, 16-VIII-1595.

${ }^{20}$ En Soria, 19-VIII-1596 Cristóbal Hernández de Zamudio, mercader de origen portugués vecino de Soria, se obligó a pagar a Baltasar Méndez Trancoso y Melchor Gómez 1.782,5 reales por el valor de 819 varas de lienzo de Flandes a 74 mrs. la vara. AHPS, PN, 203-420-219.

${ }^{21}$ En Soria, 19-VII-1596 Blasco Herrero, mercader vecino de Soria, se obligó a pagar a Baltasar Méndez Trancoso y Melchor Gómez el dinero que les adeudaba por la compra de dos docenas de corchetes de millares, 6 rebenas grandes, 10 millares de alfileres, una docena de papeles de alfileres chiquitos, 4 papeles de alfileres, 3 papeles de agujetas y 4 piezas de lienzo de lo ancho, con 156 varas. AHPS, PN, 203-420-220 y 252.

${ }^{22}$ Noticia de la compra de las lanas del esquileo de 1597 a Bernardino de las Heras, por Baltasar Méndez Trancoso y Pedro Álvarez, en escritura de obligación otorgada por este último en Soria, 21-VIII-1597, en AHPS, PN, 205-422-345. En octubre de 1596 a Baltasar Méndez todavía se le identifica como vecino de Trancoso. AHPS, PN, 257-526-86, Soria, 6-X-1596.

${ }^{23}$ Consta que ya residía en San Juan de Luz en 1601 por un documento conservado en los protocolos notariales sorianos, que pone de manifiesto que mantenía relaciones de negocios con Juan García de Tardajos, mercader soriano de origen judeoconverso, de quien había tomado a renta su lavadero en 1596. AHPS, PN, 211-432-79. 
Nos hemos detenido en dar cuenta pormenorizada de todos estos detalles de la trayectoria de Baltasar Méndez Trancoso, aunque hemos pasado por alto otros muchos para evitar resultar prolijos, porque nos proporciona una buena ilustración de cómo los mercaderes judeoconversos de origen portugués se adentraron de forma progresiva en el negocio de la exportación de lanas finas de la región soriana en las últimas décadas del siglo XVI. En su caso sabemos con certeza que su dedicación a este trato se inició en una fase relativamente avanzada de su carrera como mercader, después de haber estado muchos años negociando con otras mercancías de muy variada índole. Y, según propia confesión, la razón principal por la que se decidió a tratar con lanas estribó en que pudo comprobar que se trataba de un negocio muy lucrativo, dado que, comprándolas y lavándolas en Soria, y llevándolas a vender a San Juan de Luz, se podían obtener unos enormes márgenes de beneficio. Las razones por las que dichos márgenes eran tan grandes no son fáciles de precisar, aunque quizás influía el hecho de que se trataba de un negocio arriesgado, teniendo en cuenta que la Monarquía hispana estuvo en guerra con Francia hasta 1598. De hecho los precios de las lanas finas estuvieron muy deprimidos en la región soriana durante toda la década de 1590 , y, aunque la cuestión no está todavía suficientemente esclarecida por falta de investigaciones, parece que uno de los motivos principales radicó en que la demanda estuvo entonces muy deprimida, porque escaseaban los mercaderes dispuestos a comprar lanas para su exportación. El hecho de que Baltasar Méndez Trancoso, un desconocido y sin experiencia previa en el negocio lanero, llegase a Soria y lograse adquirir una de las pilas de más reputación de la ciudad, la de Diego de Medrano, señor de San Gregorio, nos confirma en esta impresión de que no abundaban entonces los mercaderes dispuestos a comprar las lanas finas sorianas. La quiebra de las grandes casas mercantiles burgalesas, que habían absorbido una parte importante de la producción lanera soriana hasta la década de 1570 , probablemente dejó un vació que no pudo ser cubierto de forma inmediata, y que aprovecharían individuos emprendedores, como el referido Baltasar Méndez Trancoso, para prosperar con relativa rapidez, aunque incurriendo en evidentes riesgos, dada la situación de enfrentamiento bélico con las potencias atlánticas en que estaba sumida entonces la Monarquía Hispánica.

Baltasar Méndez Trancoso se diferenció de los grandes mercaderes exportadores extranjeros que durante el siglo XVII acapararon gran parte de la producción lanera de Soria y su Tierra, en especial las pilas de mayor tamaño y reputación, en el hecho de que fue un individuo que se implicó personalmente en la gestión de su negocio, y que recorrió las sierras sorianas, para concertar directamente con los ganaderos la compra de sus lanas, y que luego se desplazó hasta San Juan de Luz para buscarles allí comprador. Nada que ver con los gran- 
des mercaderes exportadores de la época de Felipe IV, avecindados en Madrid, varios de ellos también de origen portugués, los cuales, sin moverse del entorno cortesano, negociaban con enormes cantidades de lanas, que nunca llegaban a ver ni tocar, salvo, a lo sumo, si se les enviaba alguna muestra para que la examinasen. Eran agentes, recibidores de lanas y encomenderos residentes en los puertos los que con su experiencia, que les permitía valorar la calidad de las fibras, garantizaban el buen funcionamiento del negocio, mientras que los mercaderes por cuenta de los cuales se compraba y vendía la mercancía se limitaban a proporcionar el necesario respaldo financiero a las operaciones. En el caso de Baltasar Méndez Trancoso la implicación personal en todas las fases y facetas del negocio fue mucho mayor. Y, ante la imposibilidad material de estar en todas partes al mismo tiempo, cuando advirtió las grandes posibilidades que ofrecía el negocio de exportación de lanas, para poder aprovecharlas mejor, optó por recurrir a la constitución de compañías con otros portugueses, instalados en puntos estratégicos, como era, por ejemplo, el puerto aduanero de Vitoria, aunque en última instancia tampoco pudo prescindir del todo del recurso a los encomenderos y los agentes. Este portugués, originario de Trancoso, fue un individuo con notable predisposición hacia la movilidad, que cambió de residencia innumerables veces a lo largo de su vida, arrastrando consigo a su familia, y que además realizó otros muchos viajes, que le llevaron a recorrer en poco tiempo muy largas distancias. Y siempre lo hizo con el objetivo de atender su negocio, para obtener de este modo el máximo beneficio posible de sus inversiones, que inició en su juventud con un capital muy reducido, casi insignificante, los 300 cruzados que le entregó su hermano en Lisboa cuando aún era muy joven.

Estos rasgos los compartió, por lo demás, con la mayor parte de los mercaderes portugueses que, por los mismos años que él, comenzaron a interesarse por el negocio de la compra de lanas finas en Soria y su Tierra, para su exportación al sur de Francia. A juzgar por las noticias aportadas por los protocolos notariales conservados, fue en la década de 1590 cuando se produjo ya de forma perceptible esta incorporación de judeoconversos nacidos en el reino de Portugal al mercado lanero soriano, en el que en muy breve plazo de tiempo lograron hacerse con una posición dominante. Y al igual que Baltasar Méndez, la mayoría de ellos fueron individuos con notable grado de movilidad, que cambiaban de lugar de residencia con frecuencia, y que en ocasiones estaban tan desarraigados que en los documentos se les identifica simplemente como «andantes en ferias» ${ }^{24}$.

${ }^{24} \mathrm{~A}$ un mismo individuo lo podemos encontrar en unas ocasiones identificado como «andante en ferias» y en otras como vecino de un lugar concreto. Así, a Alejo Gómez de Santiago se le identifica en 1605 como «portugués andante en ferias», mientras que en 1607 se dice que es vecino de Tordesillas. 
Otros varios, por su parte, aparecen calificados como «estantes en Soria», sin precisar si tenían adquirida la vecindad en algún otro lugar, bien de la Corona de Castilla o de fuera de ella. Es el caso, por ejemplo, de Diego y Jorge Rodríguez, Tomás y Antonio Brandon, Hernán Gómez, Diego de la Costa Pereira y Manuel Páez, todos los cuales aparecen identificados de esta manera en documentos de los años 1595, 1596 y 1597, aunque en otras fechas de algunos de ellos se nos informa que eran vecinos de otras ciudades castellanas, como Madrid o Haro. En cualquier caso se trataba siempre de vecindades de carácter muy inestable, que llegaron a ser denunciadas en ocasiones como ficticias, pues cuando se trataba de localizar a alguno de estos portugueses en los lugares donde habían declarado estar avecindados no se hallaba rastro de ellos, ni de sus haciendas ${ }^{25}$. Por otra parte llama la atención advertir que algunas de las ciudades de las que eran vecinos estaban ciertamente muy alejadas de las rutas por donde solían transitar las lanas sorianas. Así, por ejemplo, Álvaro de Paz, que efectuó compras en Soria en 1599, aparece como vecino de Granada ${ }^{26}$, mientras que los miembros de una compañía que en 1597 adquirió las lanas de Juan de Barrionuevo, vecino de Soria, se repartían por las ciudades de Murcia, Ciudad Rodrigo y Zamora ${ }^{27}$.

La mayoría de los portugueses que llegaron a Soria a negociar con lanas en la década de 1590 fueron, en consecuencia, individuos desarraigados en continuo movimiento, con intereses mercantiles muy diversificados, y que tomaban a su cargo prácticamente todas las tareas relacionadas con el trato lanero, desde la concertación de las compras con los ganaderos, hasta el lavado y ensacado de las lanas, e incluso su posterior venta en los puertos del sur de Francia. A este respecto llama la atención advertir que, a pesar de su falta de relación previa con la región soriana, en su afán por hacer prosperar su negocio, no dudaron en hacerse cargo personalmente de las tareas de lavado y ensacado de las lanas, que los mercaderes exportadores acostumbraban a delegar en destajeros sorianos. Así, nos consta que tomaron a renta algunos de los lavaderos existentes en la

${ }^{25}$ Tomamos la referencia de estas denuncias de Alberto Angulo MoRALES, «En poco tiempo vienen ricos e hazen a sus amos pobres. De factores o encomenderos a protagonistas directos del gran comercio internacional (siglos XV-XVII)», en Ernesto GARCía FERnáNDEZ (ed.), Bilbao, Vitoria y San Sebastián: Espacios para mercaderes, clérigos y gobernantes en el Medievo y la Modernidad (Bilbao 2006), págs. 79-116: 94.

${ }^{26}$ Ese año compró 807 arrobas de lana a Pedro de Burgos, mercader vecino de Soria. AHPS, PN, 239-481-433.

${ }^{27}$ La compañía formada por Garcí Méndez, vecino de Murcia, Diego Enríquez y Francisco de Valverde, vecinos de Ciudad Rodrigo, y Sebastián Fernández de Reyna, vecino de Zamora, concertó en marzo de 1597 la compra a Juan de Barrionuevo, platero, de 1.100 arrobas de lana AHPS, PN, 238-480-96 
jurisdicción. En concreto Jorge y Diego Rodríguez arrendaron en 1595 de María Jiménez de Cabredo, viuda de Cristóbal Hurtado de Mendoza, señor de Hinojosa de la Sierra, el que ésta poseía en dicha villa a orillas del Duero, por una renta anual de 300 reales $^{28}$. La compañía de Melchor Gómez y Baltasar Méndez Trancoso ya referimos que tuvo a renta por estos mismos años el que en la ciudad de Soria poseía el mercader soriano, de origen judeoconverso, Juan García de Tardajos. Por otra parte, la compañía constituida por portugueses vecinos de Murcia, Ciudad Rodrigo y Zamora que adquirió en 1597 las lanas del platero Juan de Barrionuevo contrató ese mismo año operarios de lavadero y realizó adquisiciones de cola, pruebas inequívocas de que se hizo cargo de su lavado ${ }^{29}$. $\mathrm{Y}$ otros varios contratos de venta de lana de desechos de lavadero efectuados por mercaderes portugueses en estos años a fabricantes pañeros de Soria y su entorno nos confirman, por si quedaba alguna duda, que en la mayor parte de las ocasiones se hicieron ellos mismos cargo del lavado de las lanas que adquirían para exportar, volcándose en una tarea de la que los grandes exportadores tendían a desentenderse.

Además de por su propensión a la movilidad en seguimiento de sus negocios, y por su espíritu emprendedor, los portugueses que irrumpen en el mercado lanero soriano en la década de 1590 se caracterizan por su perfil de compradores de modesta talla, que no adquirían grandes cantidades de lanas, rara vez se hacían con las pilas de mayor tamaño y reputación, y, además, se interesaban por negociar con otros muy variados productos. Es el caso, por ejemplo, de Marcos Rodríguez, avecindado en la villa riojana de Haro, quien en el verano de 1595 realizó varias compras de lanas y añinos a pequeños y medianos propietarios de la villa serrana de Carrascosa, a uno de los cuales adquirió también una pequeña partida de 181 carneros viejos capados ${ }^{30}$.

Por otra parte, no se interesaron exclusivamente por el trato con lanas finas de ganado trashumante, las llamadas estremeñas, sino que también nos consta que adquirieron lanas churras y riberiegas ${ }^{31}$, aunque no conocemos bien el destino

${ }^{28}$ AHPS, PN, 114-245, Soria, 6-VII-1595.

${ }^{29}$ Contrato firmado por esta compañía con Antón de Grandes para servirles como marcador de las sacas que hiciesen en sus lavaderos, con sueldo de 7 ducados por mes, más comida, en AHPS, PN, 238-480-94, Soria, 13-III-1597. Contrato de la compra de la cola necesaria para el lavadero (ibíd., fol. 98).

${ }^{30}$ Los contratos en AHPS, PN, 243-488. A Francisco Ruiz le compró 214 arrobas de lana y 38 de añinos. A Miguel Antón y Antón Romero 464 arrobas de lana y 58 de añinos. Y, a Miguel Antón además 181 carneros viejos capados. En todos los casos los ganaderos concedieron pago aplazado al mercader comprador.

${ }^{31}$ Sobre los diversos tipos de lana con los que se negoció en la región soriana, vid. Máximo 
que les dieron. Sí nos consta, en cualquier caso, que algunos se interesaron por el trato con fabricantes de paños de las aldeas serranas, a los que proporcionaron materia prima, y no sólo procedente de los desechos de lavadero de las lanas compradas para exportar. Así nos lo testimonia, por ejemplo, la venta efectuada por dos mercaderes vecinos de Trancoso a Antón Martínez del Rincón, vecino de Bretún, aldea de Yanguas, de cierta cantidad de añinos por un valor total de 18.000 reales, luego rebajados a 16.000, que éste se obligó en junio de 1606 a pagarles a razón de 1.000 reales cada año, entregados en Vitoria en poder de Antonio Méndez, hermano de los susodichos ${ }^{32}$. Dado, no obstante, que la cantidad de añinos vendida en esta ocasión debió ser muy grande, a juzgar por su elevado valor, entendemos que el comprador no debía ser un simple fabricante pañero, sino más bien un tratante que, o bien revendía a pequeños fabricantes de las aldeas de la Tierra de Yanguas, o bien tenía intención de llevar los añinos en sus recuas a los puertos del Cantábrico para revenderlos allí a mercaderes exportadores. Pero, como quiera que fuese, esta operación nos confirma que los portugueses que negociaron en la región soriana en esta primera etapa no se limitaron a comprar lanas y añinos para sacarlos fuera de Castilla, sino que parte también los revendieron en esta misma región.

La mayoría de los mercaderes portugueses a los que encontramos negociando con lanas churras y riberiegas durante la década de 1590 son identificados en los documentos, no obstante, como vecinos de Soria. Y algunos de ellos, en efecto, pertenecían a familias arraigadas en esta ciudad desde hacía ya varias décadas, y que lo continuaron estando durante el siglo XVII, que mostraron un fuerte interés por la inversión en la fabricación de paños, como es el caso de los Oporto-Azambújar, Rico o Méndez, entre otros. Pero junto a ellos también encontramos individuos que, según todos los indicios, estuvieron avecindados en Soria sólo de forma temporal, habiendo acudido a ella atraídos por el señuelo de las lanas, que no bastó, sin embargo, para retenerlos en esta ciudad durante mucho tiempo. Éste podría ser el caso, por ejemplo, de Pedro Gómez, quien en 1593 adquirió importantes cantidades de añinos churros en la villa de Deza, fronteriza con Aragón, a los que desconocemos qué destino dio ${ }^{33}$.

DiAgo HERnANDO, «El mercado lanero en la región soriana durante los siglos XVI y XVII: Tipología y destino de las lanas», Celtiberia 96 (2002), págs. 47-88.

${ }^{32}$ AHPS, PN, 2777-4740-62, Yanguas, 1-VI-1606.

${ }^{33}$ Por 4 contratos firmados en mayo y junio de 1593 nos consta que adquirió un total de 500 arrobas de añinos, a 11,5 reales la arroba. AHPS, PN, 144-301. 
ACELERACIÓN DEL PROCESO DE CONTROL DE LAS EXPORTACIONES DE LAS LANAS FINAS SORIANAS POR LOS MERCADERES PORTUGUESES DURANTE EL REINADO DE FELIPE III (1598-1621)

En claro contraste con lo ocurrido durante los últimos años del reinado de $\mathrm{Fe}$ lipe II, cuando la penetración de los mercaderes portugueses en el negocio de la exportación de lanas finas de la región soriana tuvo lugar de forma todavía muy ocasional y puntual, en el de su sucesor, Felipe III, los miembros de la «nación» portuguesa llegaron a hacerse en muy breve plazo de tiempo con el pleno control de un segmento muy importante de dicho mercado, y, aunque no llegaron a monopolizarlo por completo, sí lograron erigirse en el grupo con mayor volumen de negocio. Sin duda este salto cualitativo fue favorecido por la autorización concedida por este monarca en 1601 a los judeoconversos portugueses para que en adelante pudiesen abandonar Portugal, a cambio de la entrega de un cuantioso donativo, la cual, a juicio de Domínguez Ortiz, desencadenó un proceso de masiva migración de familias pertenecientes a esta minoría desde Portugal a la Corona de Castilla, en donde se desparramaron a todo lo largo y ancho de su geografía ${ }^{34}$.

A partir de 1602, en efecto, una vez superada la grave crisis de las exportaciones de lanas finas sorianas a los mercados atlánticos que se produjo en el tránsito del siglo XVI al XVII, y que propició que temporalmente las grandes cabañas buscasen una salida alternativa para sus lanas en el mercado italiano ${ }^{35}$, los mercaderes portugueses adquirieron un protagonismo sin precedentes en el negocio de la contratación lanera en esta región. Una buena prueba del salto cualitativo que en estos años se produjo nos lo proporciona la constatación del hecho de que a partir de 1602 fueron sin interrupción individuos pertenecientes a esta minoría los que adquirieron las pilas de mayor tamaño y reputación del partido mesteño soriano. Entre ellas cabe destacar la del alférez mayor de Soria, Antonio López de Río, que en 1602 alcanzó la astronómica cifra de 6.000 arrobas $^{36}$, la cual a partir de

${ }^{34}$ Vid. Antonio Dominguez Ortiz, Política y Hacienda de Felipe IV (Madrid 1960), pág. 128. Durante el siglo XVI se habían alternado los períodos en que los judeoconversos pudieron salir libremente de Portugal con los períodos en que les estuvo prohibida la salida de dicho reino. Vid. María José Pimenta Ferro Tavares, Los judios en Portugal (Madrid 1992), págs. 175 y ss y 320 y ss.

${ }_{35}$ Nos referimos a este fenómeno, que en gran medida fue consecuencia de las medidas de embargo contra Flandes dictadas por Felipe III nada más acceder al trono, en 1598, en Máximo DiAgo HERNANDO, «El mercado lanero en la región soriana durante los siglos XVI y XVII: Tipología y destino de las lanas», Celtiberia 96 (2002), págs. 47-88.

${ }^{36}$ Sobre la importancia de la explotación ganadera de los miembros de este linaje, y la reputación de sus lanas, vid. Máximo Diago Hernando, «Una explotación trashumante en la Castilla moderna: La cabaña de los Río de Soria», Historia Agraria 48 (2009), págs. 13-44. 
ese ejercicio fue adquirida año tras año por portugueses durante un largo período de tiempo, mientras que con anterioridad a esta fecha nunca había ido, ni siquiera en parte, a poder de miembros de esta «nación». Pero, además de ésta, los portugueses también lograron adquirir a partir de estos primeros años del siglo XVII la mayoría de las pilas de mayor tamaño y reputación entonces existentes en el mercado soriano ${ }^{37}$. Es el caso, por ejemplo, de las de los diversos miembros de los linajes de Sanz Cadima y Salcedo, quienes entre 1602 y 1630 les entregaron partidas de extraordinaria envergadura, como, por ejemplo, la de 1608 de Martín Sanz Cadima, vecino de Gallinero, y su sobrino Francisco de Salcedo, señor de la torre de Aldealseñor, que alcanzó la cifra record de 6.339 arrobas de lana, sin añinos ${ }^{38}$. Otro destacado linaje al que también pasaron a comprar de forma continuada sus lanas mercaderes portugueses fue el de los Carrillo, de Vinuesa, que, del mismo modo les proporcionó partidas de enorme envergadura. Así, Alonso Carrillo, sumando a sus lanas las de otros parientes suyos, les vendió en 1606 un total de 5.307 arrobas, y en 1610 en torno a las 5.000, facilitándoles además la utilización de un lavadero que poseía en dicha aldea serrana para que las beneficiasen en él, a cambio del pago de una renta de 1.000 reales $^{39}$.

Además de acaparar las mayores y más reputadas pilas, los portugueses concertaron en estos años otros muchos contratos que les permitieron hacerse con una importante porción de la producción de lana fina de Soria y su Tierra. En particular les reportaron importantes cantidades de lanas los contratos concertados con vecinos de Soria especializados en el negocio de la reventa, que compraban lanas a pequeños y medianos ganaderos de las sierras en el otoño, invierno y primavera anteriores al esquileo, adelantándoles dinero, y las revendían poco después de esquiladas a mercaderes exportadores, quienes por su parte también solían diferir el pago varios meses tras la entrega de la mercancía. Eran individuos, en muchos casos también de origen judeoconverso ${ }^{40}$, como Juan García de Tardajos, su pariente el licenciado Juan García, médico, o el doctor Santa Cruz, por citar sólo tres de los más activos en las dos primeras décadas del siglo XVII. Con todos ellos pasaron a negociar de forma sistemática los exportadores por-

${ }^{37}$ Información sobre los mayores propietarios de ganado trashumante en Soria en los siglos XVI y XVII en Máximo Diago Hernando, «Los caballeros ganaderos de Soria y su Tierra durante los siglos XVI y XVII. Contribución al estudio del grupo de los grandes señores de ganados mesteños», Celtiberia 97 (2003), págs. 127-172.

${ }^{38}$ AHPS, PN, 340-637-735.

${ }^{39}$ Para 1606, vid. AHPS, PN, 100-223-292 y para 1610, ibíd. 104-230-86.

${ }^{40}$ Sobre el origen judeocoverso de muchos de los mercaderes de la ciudad de Soria en el siglo XVI Vid. Máximo Diago Hernando, «Los judeoconversos en Soria después de 1492», Sefarad 51 (1991), págs. 259-297. 
tugueses, comprándoles año tras año partidas de cierta envergadura, que en ocasiones superaban las 2.000 arrobas por contrato, al tiempo que los sorianos, por su parte, también solían concertar en un mismo ejercicio varios contratos con diferentes exportadores, lo que da idea de su elevado volumen de negocio ${ }^{41}$.

La proporción de la producción lanera soriana que en las primeras décadas del siglo XVII llegaron a acaparar los mercaderes portugueses en su conjunto fue considerable, aunque las cantidades adquiridas por cada uno de ellos en particular no fueron, salvo excepciones, muy grandes. El mercado estuvo, en efecto, en este período bastante fragmentado si comparamos con momentos posteriores del siglo XVII, puesto que el número de operadores fue en estas primeras décadas bastante elevado, y no se advierte la presencia de figuras descollantes, que adquiriesen grandes cantidades de lanas y permaneciesen en el negocio durante bastantes años seguidos. Por el contrario, salvo raras excepciones, como la del portugués Antonio López, vecino de San Sebastián, que compró en solitario al alférez mayor de Soria una partida de lanas de 6.000 arrobas en 1602, y volvió a adquirir su pila al año siguiente, también en solitario, lo habitual fue que todos los contratos de compra de partidas de lana de cierta envergadura se concertasen en nombre de compañías en las que se integraban varios mercaderes, todos ellos, por supuesto, portugueses, y con frecuencia miembros de una misma familia. Y la nómina de mercaderes activos en cada ejercicio estuvo renovándose constantemente, con frecuentes entradas y salidas de individuos que, además, en cada ocasión aparecían como vecinos de un lugar distinto.

Dado que nuestra principal fuente de información para analizar la presencia de los portugueses en el mercado lanero soriano han sido los protocolos notariales, resulta arriesgado proponer valoraciones de carácter estadístico. Pero, al menos, sí conviene tener en cuenta algunas referencias puntuales que nos confirman el alto grado de fragmentación del mercado y el gran número de miembros de la «nación» portuguesa, todos ellos de origen converso, que trataron en lanas en la región soriana en los primeros años del siglo XVII. Así, sabemos que en 1608 un tal Luis de Salazar seguía pleito contra al menos 18 mercaderes portugueses, porque no habían registrado las lanas que habían comprado y lavado en Soria «y enviado a navegar y sacar de estos reinos», aunque el número de indi-

${ }^{41}$ Así, por poner un ejemplo ilustrativo, recordaremos que el licenciado Juan García, médico, realizó en el año 1614 los siguientes contratos de venta de lanas a portugueses. A Antonio de Soria le vendió 658 arrobas de sus propios ganados a 27 reales. A Francisco de Acosta Cardoso le vendió a 24 reales 1.196 arrobas de lana, que él había comprado en las aldeas de Cirujales, Carrascosa, Narros y Castilfrío. A Francisco Manuel y Francisco López, les vendió a 25 reales 2.102 arrobas de lana que había comprado en Vinuesa. Y a Nicolás Ferraz le vendió 231 arrobas de añinos a 35 reales. Los contratos en AHPS, PN, 226-462-564, y 347-645-55, 57 y 79. 
viduos implicados en estos negocios mercantiles debía ser mucho más elevado, ya que, además de a ellos, se alude en el documento a «los demás portugueses de sus compañías» ${ }^{42}$.

Por su parte, para poder evaluar con un mayor grado de precisión la proporción de la producción lanera soriana destinada a la exportación que llegaron a acaparar los miembros de la «nación» portuguesa en estas primeras décadas del siglo XVII disponemos de otra valiosa fuente de información en los registros que por ley estaban obligados a efectuar ante los escribanos de Soria quienes compraban lanas para exportarlas, que se conservan en los protocolos notariales para diversos años a partir de 1616, aunque, según todos los indicios, sólo de forma fragmentaria. Pues bien, todas las partidas que aparecen mencionadas en los registros conservados para el año 1616 son de portugueses, aunque de esta constatación no cabe deducir que ese año fuesen los únicos que exportaron lanas en la región soriana, pues la cantidad de arrobas registradas ascendió en ese ejercicio a tan sólo 20.139, cifra muy inferior a la de los demás años para los que se dispone de datos, por lo cual deducimos que los disponibles para ese año son muy incompletos. Al siguiente, en 1617 fueron ocho los mercaderes que declararon haber comprado lanas para exportar, de los cuales todos eran portugueses, menos uno, originario de la aldea serrana de Yanguas, aunque residente en aquellos momentos en San Sebastián ${ }^{43}$. En 1618 seis de los siete mercaderes que declararon haber comprado lanas para exportar fueron portugueses, mientras que en 1619 y en 1620 descendió un poco la proporción, aunque se siguió manteniendo alta, pues fueron cinco de un total de siete. 1621 fue el año en

${ }^{42}$ La relación nominal de estos portugueses con los que seguía pleito Luis de Salazar figura en una carta de poder otorgada a un procurador, en Soria, 1-IX-1608. AHPS, PN, 296-580-329. Sus nombres eran: Nicolás Ferraz, Pedro de Silva, Manuel Rodríguez, Manuel Díez, Santiago Gómez, Fernán Simón, Francisco Juan, Francisco Manuel, Antonio Fernández, Nicolás de Acebedo, Mendo López, Antonio Brandon, Melchor Méndez, Francisco Valverde y Villalobos, Hernando Quirós, Francisco Tejera, Sancho Méndez y Fernando Gómez. En otra carta de poder otorgada en la misma fecha (ibíd., fol. 632) aludió a los pleitos que seguía por el mismo motivo con Juan de Biduña «y otros portugueses», por lo que el número de portugueses activos en el mercado lanero soriano en esas fechas debía ser muy superior a la veintena.

${ }^{43}$ Sobre el destacado papel desempeñado por los yangüeses, es decir los originarios de la villa de Yanguas y las aldeas de su Tierra, en el comercio lanero durante el siglo XVII, vid. Máximo Diago Hernando, «Mercaderes propietarios de ganado trashumante en la cuadrilla mesteña soriana en los siglos XVI y XVII», Studia Historica. Historia Moderna 26 (2004), págs. 255-282; e IDEM, «Comerciantes campesinos en la Castilla bajomedieval y moderna: La actividad mercantil de los yangüeses entre los siglos XIV y XVII», Historia. Instituciones. Documentos 32 (2005), págs. 115-144. 
que mayor número de mercaderes efectuaron registros, al ascender a once, y de nuevo fue mayoritario el grupo de los portugueses, con seis representantes, mientras que el resto fueron mercaderes de la propia región soriana, en concreto tres procedentes de aldeas de la Tierra de Yanguas, uno de la villa de Lumbreras de Cameros y uno de la propia ciudad de Soria. Por fin, en 1622, último ejercicio para el que se nos han conservado registros, de un total de cinco mercaderes que declararon haber comprado lanas para exportar, cuatro fueron portugueses.

Consideramos prácticamente seguro que, además de estos mercaderes que aparecen efectuando registros en los protocolos conservados, hubo otros que también compraron lanas para exportar, que quizás registraron ante otros escribanos. Y, por supuesto, el número de individuos implicados en el negocio exportador fue bastante mayor, dado que en los registros sólo suele aparecer el nombre de uno de los integrantes de las compañías por cuenta de las que se compraban las lanas. Pero, en cualquier caso, entendemos que los datos proporcionados por los registros notariales sorianos entre 1616 y 1622 no dejan lugar a dudas de que el grupo hegemónico en el mercado de exportación de lanas de esta región fue en ese período el portugués, tras el que se situó, a bastante distancia, el constituido por mercaderes locales, preferentemente yangüeses y vecinos de villas cameranas como Lumbreras ${ }^{44}$.

A partir de 1622 se interrumpe la primera serie de registros conservados en los protocolos notariales sorianos, y no volvemos a disponer de datos seriales de este género hasta el año 1638. Pero a partir de esta fecha en los registros conservados advertimos que ya no se da un predominio tan marcado de las compañías portuguesas como entre los años 1616 y 1622. Por supuesto, siguen apareciendo en estos registros nombres de exportadores portugueses, los cuales estaban ya concentrados en su gran mayoría en Madrid, y en un alto porcentaje eran asentistas al servicio de la Monarquía. Pero, al mismo tiempo, una parte muy importante del mercado había pasado a estar controlada por otros mercaderes de muy variada procedencia, aunque en su mayoría extranjeros, entre los cuales encontramos ingleses, franceses, flamencos, loreneses e italianos.

${ }^{44}$ Para más detalle puede consultarse la información que ofrecemos sistematizada en cuadro adjunto, en que indicamos la proporción del total de lanas que aparecen declaradas en los registros de la ciudad de Soria que fueron adquiridas por mercaderes portugueses. Como puede observarse, hay diferencias importantes en la cantidad total de lanas declaradas cada año, que obedecen, más que a bruscas alteraciones de la producción, que también las hubo, al hecho de que los registros son fragmentarios. 
Relación de mercaderes portugueses que registraron lanas para exportar en Soria entre 1616 y $1622^{45}$

\section{AÑo 1616}

Todos los que registran son portugueses. Registro muy incompleto:

Francisco de Acosta Fonseca, vecino Valladolid: 9.660 arrobas.

Antonio de Figueroa, vecino de Madrid: 2.979 arrobas.

Francisco López, vecino de Soria: 3.000 arrobas.

Nicolás Ferraz, vecino de Soria: 4.500 arrobas.

TOTAL REGISTRADO: 20.139 arrobas

\section{AÑo 1617}

De 8 partidas registradas 7 son de portugueses:

Antonio Méndez Soto, vecino de Madrid: 7.000 arrobas.

Gonzalo Fernández, vecino de Valladolid: 3.000 arrobas.

Antonio de Soria, vecino de Medina de Rioseco, y Antonio de Acosta Tejera, vecino de Valladolid: 4.500 arrobas.

Fernando de Quirós, vecino de Madrid: 8.020 arrobas.

Francisco López, vecino de Soria: 3.500 arrobas.

Pablo Rodríguez de Aguiar, vecino de Madrid: 4.080 arrobas.

Nicolás Ferraz, vecino de Soria: 1.171 arrobas $^{46}$.

TOTAL REGISTRADO: 34.551 arrobas, de ellas 28.271 por portugueses, $81,8 \%$.

\section{AÑo 1618}

De 7 partidas registradas 6 son de portugueses:

Antonio de Acosta de Paz y Francisco de Acosta Fonseca, vecinos de Valladolid: 8.000 arrobas.

Pedro Álvarez y Francisco de Acosta Fonseca, vecinos de Valladolid: 5.500 arrobas.

\footnotetext{
${ }^{45}$ Tomamos los datos de los registros efectuados ante el escribano Miguel de La Peña, en AHPS, PN, cajas 441-447.

${ }^{46}$ No se conserva el registro. Nos consta por la escritura de obligación de Francisco González de Río con Nicolás Ferraz. AHPS, PN, 230-468-306. 
Bartolomé Gómez, vecino de Madrid: 1.600 arrobas.

Francisco López, vecino de Soria: 2.600 arrobas.

Fernando de Quirós, vecino de Madrid: 7.808 arrobas.

Antonio Méndez Soto: 7.609 arrobas $^{47}$.

TOTAL REGISTRADO: 38.117 arrobas, de ellas 33.117 por portugueses, $86,8 \%$.

\section{AÑo 1619}

De 7 partidas registradas 5 son de portugueses:

Francisco López de Quirós, Enrique Méndez y Fernán Báez de Quirós, vecinos de Madrid: 9.900 arrobas.

Fernán Báez de Quirós, vecino de Madrid, 1.305 arrobas.

Francisco López, vecino de Soria: 2.000 arrobas.

Pedro Álvarez, vecino de Valladolid, y Antonio de Soria, vecino de Medina de Rioseco: 5.500 arrobas.

Bartolomé Gómez Sánchez, vecino de Madrid: 1.120 arrobas. TOTAL REGISTRADO: 30.465 arrobas, de ellas 19.825 por portugueses, $65,07 \%$.

\section{AÑo 1620}

De 7 partidas registradas 5 son de portugueses:

Pedro Álvarez, vecino de Valladolid, y Antonio de Soria, vecino de Medina de Rioseco: 6.000 arrobas.

Pedro Álvarez, Antonio de Acosta de Paz y Duarte de Acosta, vecinos de Valladolid: 3.000 arrobas.

Martín Rodríguez, vecino de Madrid: 7.500 arrobas.

Francisco López de Quirós y su tío Fernán Báez de Quirós, vecinos de Madrid: 10.000 arrobas.

Juan de Cardona, vecino de Soria: 2.850 arrobas.

TOTAL REGISTRADO: 41.350 arrobas, de ellas 29.350 por portugueses, $70,9 \%$.

${ }^{47}$ No se conserva el registro. Hemos sumado las cantidades que aparecen en seis contratos de obligación. 


\section{AÑo 1621}

De 11 partidas registradas 6 son de portugueses:

Francisco de Acosta Fonseca y su cuñado Antonio de Acosta de Paz, vecinos de Valladolid: 11.300 arrobas.

Pedro Álvarez, vecino de Valladolid: 4.200 arrobas.

Jerónimo de Fonseca, vecino de Madrid: 4.500 arrobas.

Enrique Méndez y Fernán Báez de Quirós, vecinos de Madrid: 10.000 arrobas.

Fernán Pérez, vecino de Valladolid: 944 arrobas.

Juan Pereira, vecino de Valladolid: 1.500 arrobas.

TOTAL REGISTRADO: 58.094 arrobas, de ellas 32.444 por portugueses, $5,8 \%$.

\section{AÑo 1622}

De 5 partidas registradas 4 son de portugueses:

Jerónimo de Fonseca, vecino de Madrid: 6.020 arrobas.

Enrique Méndez, vecino de Madrid: 7.405 arrobas.

Enrique Méndez y Francisco López de Quirós: 5.550 arrobas.

Juan Pereira, vecino de Valladolid: 800 arrobas.

TOTAL REGISTRADO: 22.775 arrobas, de ellas 19.775 por portugueses, $86,8 \%$.

PERFIL DE LOS MERCADERES PORTUGUESES EXPORTADORES DE LANAS FINAS SORIANAS DURANTE EL REINADO DE FELIPE III

Como hemos adelantado, el número de portugueses de origen judeoconverso que participaron en el negocio de exportación de lanas en la región soriana durante las dos primeras décadas del siglo XVII fue extraordinariamente elevado, y por ello no resulta fácil abordar una caracterización del mismo en su conjunto. Aún a riesgo de generalizar y ofrecer una imagen ligeramente deformada de la realidad, trataremos, no obstante, de llamar la atención sobre algunos rasgos que consideramos definitorios de un número muy importante de individuos pertenecientes a este grupo, y que permiten diferenciarlos de otros portugueses de más talla como hombres de negocios, que desarrollaron su actividad durante el reinado de Felipe IV, alcanzando entonces un notable protagonismo en el mundo de las altas finanzas como prestamistas al servicio 
de la Monarquía, pero que también desarrollaron una extraordinaria actividad como exportadores de lanas.

Para empezar, los portugueses que nos encontramos negociando en lanas en la región soriana durante el reinado de Felipe III son individuos que tenían fijada su residencia en lugares muy diversos de la geografía peninsular, tanto de la Corona de Castilla como del reino de Portugal, y también, al otro lado de los Pirineos, en la región del sudoeste francés, y, en menor número, en otros puertos del Atlántico como Rouen, en Normandía. En ningún otro momento de los siglos XV, XVI y XVII encontramos en esta región tratando con lanas tanta gente de tan diversa procedencia geográfica, pero que al mismo tiempo formaban parte de un mismo grupo o «nación», dotado de una fuerte identidad, como era el constituido en la primera mitad del siglo XVII por los judeoconversos portugueses. Era la lógica consecuencia de la extraordinaria movilidad de la que entonces hicieron gala los miembros de esta «nación», desperdigados a lo largo y ancho de la geografía de la Europa Occidental en busca de la ganancia mediante el ejercicio del comercio, siempre dispuestos a reorientar sus inversiones hacia el negocio que mayores beneficios pudiera reportarles.

Los mercaderes de origen portugués que compraron lanas para exportar en la región soriana durante el reinado de Felipe III fueron en su mayoría individuos que no llegaron a avecindarse ni en Soria ni en ningún otro núcleo de su entorno, lo que no les impidió a muchos de ellos frecuentar esta ciudad y su comarca para atender asuntos relacionados con el trato lanero, especialmente durante la temporada de los lavaderos. Algunos de ellos seguían estando avecindados en ciudades del reino de Portugal como La Guardia (Guarda), de donde era vecino Jerónimo Méndez, quien en el verano de 1606 se encontraba en la aldea serrana de Vinuesa ${ }^{48}$, y también los hermanos Francisco, Juan y Antonio Méndez Enríquez, hijos de Francisco Méndez Enríquez, quienes en 1608 compraron al alférez mayor de Soria, Antonio López de Río, 300 sacones de lana lavada y 1.000 arrobas de añinos ${ }^{49}$. Por su parte de Olivenza, perteneciente entonces a Portugal,

${ }^{48}$ Estando en Vinuesa, otorgó poder al portugués Antonio Brandon, vecino de Madrid, para que le pudiese obligar como fiador para un contrato de compra de lanas a ganaderos visontinos por valor de $102.481,75$ reales, y para otro contrato por valor de 29.854,5 reales, AHPS, PN, 100-22329, Vinuesa, 23-VIII-1606. Por otros documentos nos consta que este Jerónimo Méndez formó una compañía junto con Antonio Brandon, vecino de Madrid, y Francisco Méndez Soro, vecino de Rouen, al servicio de la cual estuvo el judeoconverso soriano Juan García de Tardajos.

${ }^{49}$ El contrato en AHPS, PN, 102-227-551. Estos vecinos de La Guardia (Guarda) no se encontraron, sin embargo, presentes en Soria a la firma del contrato, sino que éste fue suscrito en su nombre por Luis Gómez Pérez, vecino de Medina de Rioseco. 
era vecino Andrés Báez Núñez, quien en 1608 realizó adquisiciones de lanas de modesta envergadura en la región soriana ${ }^{50}$.

Muchos otros de los portugueses que estuvieron negociando con lanas en esta región durante las dos primeras décadas del siglo XVII habían adquirido la vecindad en ciudades castellanas, no siempre relacionadas directamente con las rutas de la lana. Entre ellas cabe destacar las dos en las que en este período llegó a tener su sede la Corte, Madrid y Valladolid, de las que fueron vecinos un elevado número de individuos integrados en compañías exportadores de lanas finas sorianas. En las ciudades portuarias de Bilbao y San Sebastián, donde se embarcaba una parte importante de la lana destinada a la exportación, también hubo avecindados varios mercaderes, mientras que a otros los encontramos identificados como vecinos de otros núcleos urbanos más alejados de la ruta de salida de las lanas como Tordesillas, Palencia, importante centro de producción pañera, o Medina de Rioseco, centro comercial que durante el siglo XVII no alcanzó, sin embargo, la relevancia que había tenido en los dos siglos anteriores gracias a sus ferias. En cualquier caso, aunque los portugueses a los que encontramos tratando con lanas en Soria se concentraron en mayor número en ciudades de la submeseta norte, también los hubo que estuvieron avecindados en ciudades de la Corona de Castilla bastante más alejadas, como, por ejemplo, Jaén, de donde era vecino en 1613 Alonso Martínez, quien en compañía con Gonzalo Méndez Enríquez, vecino de Madrid, compró en 1613 una gran partida de lanas a dos destacados señores de ganados, Francisco de Salcedo y Martín Sanz Cadima, de la que se hicieron 256 sacones que fueron transportados a Pamplona ${ }^{51}$.

Por fin, un tercer ámbito en el que habían adquirido la vecindad varios de los miembros de las compañías exportadoras que negociaron con lanas sorianas en este período es el de las ciudades portuarias de las costas atlánticas de Francia, desde Biarritz, Bayona o San Juan de Luz hasta Rouen en Normandía, pasando por Burdeos ${ }^{52}$. En bastantes casos los judeoconversos portugueses avecindados en alguna de estas ciudades francesas participaron en la adquisición de lanas sorianas como miembros de compañías en las que también estaban integrados otros parientes suyos vecinos de ciudades de la Corona de Castilla. Pero en otras

${ }^{50}$ Sobre la compra de 548,5 arrobas de lana estremeña a García Malo de Río, vid. AHPS, PN, 217-445-350, Soria, 1-X-1608.

${ }^{51}$ AHPS, PN, 224-458-375.

${ }^{52}$ Sobre las comunidades de conversos portugueses en las ciudades francesas, vid. Gérard NAHON, «Comunidades españolas y portuguesas de Francia (1492-1992)», en Henry MECHOULAN (ed.) Los judios de España. Historia de una diáspora (1492-1992) (Madrid 1993), págs. 125156. 
ocasiones nos consta que efectuaron compras por su propia cuenta, utilizando los servicios de intermediación de algún otro portugués residente en territorio castellano. Así, por ejemplo, en 1618 Manuel Díez Sánchez, vecino de Rouen, compró 1.330 arrobas de lana segoviana a uno de los principales señores de ganados de la oligarquía soriana, Don Rodrigo de Salcedo, caballero de Santiago, aunque cerró el contrato en su nombre Bartolomé Gómez Sánchez, portugués vecino de Madrid $^{53}$.

Además de su notable dispersión geográfica, un segundo rasgo fundamental que caracteriza a los portugueses que negociaron con lanas sorianas en las dos primeras décadas del siglo XVII es que se trataba de individuos con limitados medios financieros, que no tenían capacidad para afrontar cada uno de ellos por separado la compra de partidas de lana de gran envergadura, y que por ello tendían a constituir compañías con gran número de miembros, para poder hacer frente así mejor a la compra de partidas de cierta entidad. Sus procedimientos habituales de contratación también sugieren que su posición financiera era relativamente frágil, pues cabe advertir que en la mayor parte de las ocasiones, tanto cuando negociaron directamente con los señores de ganados como cuando lo hicieron con los mercaderes intermediarios sorianos, exigieron a éstos que les concediesen aplazamientos de varios meses, e incluso años, en el pago de la mercancía recibida. Además entre los grandes señores de ganados sorianos que les vendieron sus lanas cabe advertir que existía cierta suspicacia hacia ellos, derivada de la falta de información segura sobre su solvencia, que se tradujo en la incorporación de algunas cláusulas inhabituales en los contratos de venta de lanas, con las que se pretendía añadir garantías adicionales frente a hipotéticos impagos. Así, por ejemplo, podemos destacar el hecho de que en la operación de venta de 300 sacones de lana lavada que realizó el alférez mayor de Soria, Antonio López de Río, a unos portugueses vecinos de La Guardia (Guarda) en 1608, concediéndoles un aplazamiento del pago de su valor de más de dos años, en cuatro plazos de igual cuantía, se estipuló que 100 de los dichos sacones permaneciesen en el lavadero de Almenar «en resguardo», hasta que se hubiese cumplido con los pagos de los dos primeros plazos ${ }^{54}$.

Las compañías por cuenta de las que se adquirieron y exportaron las lanas estuvieron con frecuencia integradas por individuos residentes en lugares muy dispares y alejados entre sí, dándose el caso de que en algunas hubo miembros

\footnotetext{
${ }^{53}$ AHPS, PN, 289-570-258, Soria, 24-IX-1618.

${ }^{54} \mathrm{El}$ contrato en AHPS, PN, 102-227-551. Se dispuso que las lanas se pagasen en 4 plazos iguales, en enero y agosto de 1609 y en abril y diciembre de 1610. Las cien sacas permanecerían retenidas en Almenar hasta fin de agosto de 1609.
} 
avecindados en ciudades de Portugal, de la Corona de Castilla y de Francia. La participación en una misma compañía de mercaderes residentes en ciudades castellanas, por un lado, y en ciudades portuarias de Francia, bien de la región del sudoeste o bien de Normandía, por otro, que se dio con bastante frecuencia, sin duda resultó muy positiva para la buena marcha del negocio de exportación de lanas, pues facilitó el reparto de tareas, y permitió en cierta medida prescindir del recurso a la colaboración de terceros. Así, mientras por un lado unos miembros de la compañía se ocupaban en Castilla de las tareas de adquisición, lavado y ensacado de las lanas, por otro los que residían en los puertos franceses tomaban a su cargo las tareas de recibirlas allí y buscar para ellas compradores, que bien podían ser fabricantes pañeros o bien mercaderes que compraban para revender a fabricantes de otras regiones, más o menos lejanas ${ }^{55}$.

En bastantes casos estas compañías tenían un marcado carácter familiar, pues integraban a padres, hijos, hermanos y tíos, y otros parientes, que a lo largo de su vida cambiaban repetidas veces de lugar de residencia, conforme lo iba exigiendo la buena marcha del negocio. Así, por poner un ejemplo ilustrativo, recordaremos que Bartolomé Febo, mercader procesado por el tribunal de la Inquisición en 1633, declaró que había nacido en Madrid hacía unos 25 años, y que, cuando tenía alrededor de 9 años, se había trasladado a Lisboa con un tío suyo, para regresar de nuevo a Madrid, a casa de otro tío, al cabo de 6 años. Pero sólo permaneció allí un mes, porque a continuación se trasladó a vivir a Rouen, donde permaneció junto con su padre y su madrastra unos 4 años, transcurridos los cuales regresó de nuevo a Madrid $^{56}$. Su caso no fue, por lo demás, excepcional sino que, por el contrario, la documentación notarial nos revela los nombres de numerosos portugueses interesados en el trato con lanas en la región soriana en las primeras décadas del siglo XVII, los cuales unos años aparecen como vecinos de ciudades castellanas, como Madrid o Valladolid, y otros son identificados como vecinos de ciudades francesas como San Juan de Luz, Bayona, Sablar o Rouen. Es el caso, entre otros, de Francisco de Acosta Fonseca, identificado como vecino de Valladolid en 1606 y de San Juan de Luz en 1608, pero que vuelve a aparecer como vecino de la ciudad del Esgueva en diversos años de la década de 1610 y por fin en 1622 ya es identificado como vecino de la ciudad francesa de Sablar.

${ }^{55}$ Por ejemplo tenemos noticia de que Francisco Ortiz, vecino de San Juan de Luz, se concertó con Carlos Pubillon, vecino de Lille, en Flandes, en que le entregaría 2.000 arrobas de lana estremeña puesta en San Juan de Luz, comprometiéndose además a comprarle en Soria y su Tierra otras 2.000 arrobas de lana, fiadas. AHPS, PN, 140-294, Soria, 13-VIII-1607.

${ }^{56} \mathrm{Su}$ declaración en AHN, Inquisición, 146-4. También declaró que durante su estancia en Rouen realizó un viaje a Amberes para «olgarse» y permaneció allí unos 20 días. Tenemos noticia de compras de lanas en Soria por Bartolomé Febo en los años 1629 y 1630. 
La extrema movilidad de los miembros de las familias judeoconversas portuguesas en estas primeras décadas del siglo XVII, unida a la fuerza que en su seno mantuvieron los lazos del parentesco, les facilitaron la consolidación de sólidas redes mercantiles en el espacio europeo occidental, que les proporcionaron la más eficaz herramienta para hacerse con el control de una fracción importante del comercio internacional en esta época. Fue por ello que entre los exportadores laneros pertenecientes a la «nación» portuguesa que operaron en la región soriana advertimos que no resultó tan frecuente e intenso el recurso a la colaboración de terceros, que asumiesen por su cuenta el desempeño de determinadas tareas, como lo fue entre otros mercaderes exportadores. Por el contrario, como ya hemos adelantado, los mercaderes portugueses, incluso cuando eran vecinos de ciudades muy alejadas de Soria, de los reinos de Francia o Portugal, o de regiones muy distantes dentro de la Corona de Castilla, como Andalucía o Murcia, frecuentaron con asiduidad las tierras sorianas, bien para cerrar personalmente los contratos de compra de lanas, o para supervisar las tareas del lavado y ensacado de las mismas. Y en esto se diferenciaron frontalmente de la mayoría de los grandes exportadores que dominaron en el mercado lanero soriano en fechas más avanzadas del siglo XVII, durante el reinado de Felipe IV, los cuales apenas hicieron acto de presencia en tierras de Soria, pues delegaron todas las tareas que el trato con lanas finas requería realizar en dichas tierras en agentes reclutados entre los mercaderes sorianos ${ }^{57}$. Los portugueses que desarrollaron su actividad durante las dos primeras décadas del siglo XVII pudieron en muy mayor medida prescindir de la colaboración de estos mercaderes locales, grandes conocedores de los entresijos del negocio lanero por tradición familiar y muchos años de experiencia, aunque de hecho no lo hicieron de forma radical, sino que por el contrario son muchos los testimonios que confirman que mantuvieron una muy estrecha relación con algunos de ellos. Para empezar ya hemos advertido cómo una parte importante de las lanas que adquirieron en la región soriana procedieron de compras efectuadas a intermediarios vecinos de la ciudad de Soria, que las habían adquirido previamente a medianos y pequeños ganaderos trashumantes de las comarcas serranas.

Por otra parte, en segundo lugar, aunque muchos de ellos comenzaron haciéndose cargo en persona de la organización de las tareas del lavado y ensacado de las lanas, tomando a renta para ello alguno de los varios lavaderos existentes

${ }^{57}$ Un ejemplo ilustrativo de esta forma de proceder nos los proporcionan algunos mercaderes flamencos que negociaron con lanas sorianas durante el reinado de Felipe IV, a los que dedicamos un análisis monográfico en M. Diago Hernando, «Actividad mercantil y financiera de los hombres de negocios flamencos en Madrid a mediados del siglo XVII», Anales del Instituto de Estudios Madrileños 41 (2001), págs. 165-206. 
en la región, pronto, a medida que sus inversiones en el negocio iban alcanzando mayores dimensiones, terminaron inclinándose por la opción de delegar esta compleja tarea en especialistas locales, los llamados «destajeros». Pero cabe advertir que éstos fueron en bastantes casos vecinos de Soria de origen portugués, que pertenecían a familias que habían arraigado en la ciudad del Duero durante el reinado de Felipe II. Es el caso, entre otros, de Simón Fernández de Oporto Azambújar, Juan Rico ${ }^{58}$, y Pablo Méndez ${ }^{59}$.

En líneas generales los mercaderes vecinos de Soria con los que más estrechamente tendieron a colaborar en sus negocios los portugueses exportadores de lanas que operaron en las primeras décadas del siglo XVII fueron individuos miembros de familias de origen judeoconverso, como era el caso del ya mencionado Juan García de Tardajos, y de su pariente, el licenciado Juan García, médico, dos de los más activos hombres de negocios de la ciudad del Duero en este período. Este último, en una declaración efectuada en el año 1608, cuando contaba 60 años de edad, manifestó que desde hacía varios años «había tratado muy particularmente con los portugueses» ${ }^{60}$. Y su colaboración con ellos llegó hasta el extremo de ofrecerse en alguna ocasión como su fiador para el pago de los derechos aduaneros debidos por determinadas partidas de lanas destinadas a la exportación ${ }^{61}$. Por su parte, Juan García de Tardajos mantuvo una estrecha relación de negocios con el portugués Antonio Brandon, vecino de Madrid, hasta el punto de que llegó a encomendarle alguna pequeña partida de sacas de lanas propias para que se las hiciese vender junto con las suyas en Normandía, y le remitiese luego el dinero obtenido de la venta ${ }^{62}$. Y esta predisposición a cola-

${ }^{58}$ Simón Fernández de Oporto Azambújar y Juan Rico tuvieron compañía «en el beneficio de lanas estremeñas de mercaderes portugueses y de otras personas», que se lavaron en el lavadero propiedad de Simón y en otros lavaderos en 1614, 1615 y 1616, noticia en AHPS, PN, 356-654-131. En los protocolos notariales sorianos abundan los contratos firmados por Juan Rico con exportadores laneros portugueses para lavarles y beneficiarles sus lanas. Por ejemplo con Gonzalo Fernández y Manuel López Téllez, vecinos de Valladolid, en 1617, AHPS, PN, 230-468-254. Con Martín Rodríguez, vecino de Madrid, en 1620, AHPS, PN, 445-785-240. Con Hernán Báez de Quirós y Enrique Méndez, hermanos vecinos de Madrid, en 1620 y 1621, AHPS, PN, 445-785-297 y 437-774-277.

${ }^{59}$ Pablo Méndez tomó a destajo en 1617 el lavado de las lanas de Hernán Báez de Quirós en los lavaderos de Soria y Tera, AHPS, PN, 230-468-278.

${ }^{60}$ AHPS, PN, 340-637-726v.

${ }^{61}$ Un ejemplo en AHPS, PN, 399-710-33, Soria, 20-IX-1606. El licenciado Juan García, médico, se obligó como fiador al pago de los derechos aduaneros debidos por las lanas que exportasen en aquel ejercicio Diego de Acosta Pereda y Alejo Gómez de Santiago, portugueses estantes en Soria.

${ }^{62}$ Noticia de una operación de este tipo en AHPS, PN, 345-642-682, Soria el 23-VIII-1612. Carta de finiquito otorgada a Antonio Brandon por María de Soria, viuda de Juan García de 
borar con exportadores de lanas pertenecientes a la «nación» portuguesa tuvo continuidad en la siguiente generación, dado que nos consta que su hijo Lucas García de Vera sirvió como agente al célebre asentista Fernando de Montesinos, vecino de Madrid, quien, por ejemplo, en 1638 le otorgó poder para comprar en la región soriana hasta un total de 10.000 arrobas de lana fina ${ }^{63}$.

\section{El ARraigo de los mercaderes laneros portugueses en Soria DURANTE EL REINADO DE FELIPE III}

Por contraste con el gran número de mercaderes de origen portugués que durante las dos primeras décadas del siglo XVII operaron con lanas en la región soriana con vistas a su exportación, fueron pocos los que en este período llegaron a arraigar en la ciudad del Duero o en alguna otra población de su entorno. Por supuesto Soria contó durante el siglo XVII con una importante minoría portuguesa, fácilmente identificable por la marcada tendencia de sus miembros a la concertación de matrimonios endogámicos. Y entre los integrantes de dicha minoría el interés por la negociación con lanas estuvo muy desarrollado, manteniéndose a lo largo de toda la centuria. Pero no se orientó de forma preferente hacia la actividad exportadora propiamente dicha, sino que por el contrario se concentró en actividades como el lavado y ensacado de lanas finas adquiridas para su exportación por otros mercaderes ${ }^{64}$, la compra de lanas churras y riberiegas para su reventa a fabricantes pañeros de las regiones soriana y camerana, y la puesta en marcha de empresas de fabricación de paños en la propia ciudad de Soria. Por contraste fueron muy pocos los portugueses avecindados en Soria para los que disponemos de noticias que nos confirmen su directa participación por cuenta propia en empresas de exportación de lanas. Uno de ellos es Diego Rodríguez, de quien nos consta su actividad como exportador lanero en $1607^{65}$, y de quien sabemos además que llegó a

Tardajos. Se hace constar que éste había enviado a Rouen por hacienda propia, aunque por orden de Antonio Brandon, 18 sacones y medio de lana estremeña lavada, que recibió en Rouen Francisco Méndez Soto. Quedaban por cobrar todavía del producto de la venta de dicha lana 103 escudos franceses, que debía enviar Francisco Méndez Soto a Antonio Brandon, y éste a su vez entregaría luego a María de Soria, vid. AHPS, PN, 345-642-682.

${ }^{63}$ AHPS, PN, 454-794-122.

${ }^{64}$ Uno de los lavaderos que funcionó en Soria durante el siglo XVII fue propiedad de una familia de origen portugués, la de los Oporto-Azambújar.

${ }^{65}$ Otorgó poder a Juan González de Heredia, administrador de las rentas reales del puerto de Salvatierra, para que se obligase en su nombre al pago de los derechos aduaneros que le correspondiese pagar por sus lanas, AHPS, PN, 360-658-375, Soria, 12-II-1607. 
arraigar en la ciudad del Duero, donde contrajo matrimonio con Margarita de Oporto Azambújar, perteneciente a una familia de origen portugués instalada en Soria desde tiempos de Felipe II, que proporcionó destacados hombres de negocios a esta ciudad durante el siglo XVII.

También fue exportador de lanas Nicolás Ferraz, quien comenzó a negociar con esta mercancía en tierras sorianas hacia 1606, cuando todavía estaba avecindado en la ciudad de Palencia ${ }^{66}$, donde a su vez residían varios de sus cuñados, hermanos de su mujer, Isabel Pereira, con los que realizaba negocios en compañía. En 1610 decidió, por fin, avecindarse en Soria, presentando como fiador para su vecindad a un mercader vecino de esta ciudad llamado Juan de Ayuso, de quien desconocemos el origen ${ }^{67}$. Y debió entonces contemplar la posibilidad de arraigar en esta ciudad, puesto que poco tiempo después dio un paso inusual entre los miembros de su «nación», al adquirir por compra a un clérigo, miembro del cabildo de la catedral de Osma aunque residente en Salamanca, un rebaño de ganado ovino de raza churra de algo más de medio millar de cabezas, que era llevado a pastar en invierno al reino de Aragón, a Alfamen, cerca de La Almunia de Doña Godina ${ }^{68}$. Fue una operación de carácter excepcional, pues es el único mercader portugués del que tenemos noticia que llegó a convertirse en propietario ganadero, aunque desconocemos cuánto tiempo mantuvo en propiedad los ganados, que, además, conviene recordar que no eran trashumantes, y por lo tanto producían un tipo de lana que no era la que habitualmente se destinaba a la exportación. A este respecto cabe dejar constancia también del hecho de que, aunque Nicolás Ferraz se interesó ciertamente por la compra de lanas finas estremeñas para su exportación, dedicó una parte importante de su actividad al trato con lanas churras y riberiegas, procedentes del esquileo de ganados estantes y trasterminantes, y así mismo adquirió en algunos ejercicios grandes partidas de añinos. Por ello nos sentimos inclinados a pensar que en su actividad como mercader lanero tuvo más peso su papel como proveedor de materia prima para la manufactura pañera castellana que su papel como exportador. Y, a este respecto, consideramos bastante significativo el hecho de que llegase a Soria procedente de Palencia, pues esta última ciudad fue en la primera mitad del siglo

${ }^{66}$ Noticia sobre compras de lanas de escasa envergadura efectuadas al mercader soriano, y propietario de ganados trashumantes, Hernando de Lumbreras en 1606 y 1607, en AHPS, PN, 100-223-281 y 101-224-284. Resulta significativo que en los contratos se contempló que Nicolás Ferraz realizase algunos de los pagos en las ferias de Mondéjar, para San Andrés de noviembre de 1606, y en las de Tendilla para Carnestolendas de 1608.

${ }^{67}$ AHPS, PN, 141-296-180, Soria, 23-IX-1610.

${ }^{68}$ AHPS, PN, 326-618-177 y 181. En el momento de realizarse la venta se contabilizaron 627 cabezas que quedaron reducidas a 585 pagaderas, valoradas a 11 reales cada una. 
XVII, junto con Segovia y los Cameros, uno de los principales focos de demanda de lanas de la región soriana, para la fabricación de mantas, cobertores, paños y bayetas $^{69}$. Por otra parte Nicolás Ferraz, aunque desplegó una intensa actividad y demostró estar dotado de notable capacidad de iniciativa y dinamismo, no fue un hombre de negocios al que podamos calificar de exitoso, pues su etapa final se vio ensombrecida por las graves dificultades financieras a las que tuvo que hacer frente, y la declaración del concurso de acreedores, tras la cual su pista desaparece de la documentación notarial soriana, y no volvemos a saber nada más de él.

Un tercer personaje identificado como portugués vecino de Soria que participó activamente en la exportación de lanas finas adquiridas a ganaderos sorianos en la segunda década del siglo XVII es Francisco López, quien aparece efectuando registros de lanas compradas para exportar en los años 1616, 1617, 1618 y 1619, y nos consta que, al menos en alguno de estos ejercicios, formó compañía con otro portugués residente en Bayona, Francisco Manuel ${ }^{70}$. Pero de este individuo no volvemos a tener noticias para fechas más tardías que confirmen que continuó residiendo en Soria, o dejó descendientes en esta ciudad, y por ello estimamos probable que su avecindamiento en esta ciudad tuviese sólo carácter temporal y terminase abandonándola, quizás para instalarse en alguna ciudad del sur de Francia o de Normandía, como hicieron otros muchos portugueses por estos años.

En conjunto, por lo tanto, cabe concluir que los miembros de la «nación» portuguesa más volcados hacia el negocio de la exportación de lanas que desarrollaron su actividad en la región soriana en las primeras décadas del siglo XVII, aunque ciertamente prodigaron bastante más sus estancias por estas tierras que otros grandes exportadores foráneos que operaron en ellas en fechas más avanzadas de este mismo siglo, mostraron escasa predisposición por fijar allí de forma estable su residencia, adoptando la vecindad en la ciudad del Duero o en algún otro núcleo del entorno, como, por ejemplo, la villa aduanera de Ágreda. Por el contrario, los más activos exportadores de origen portugués que operaron con lanas sorianas en este período fueron individuos con notable grado de movilidad, que cambiaban de residencia cada poco tiempo y vivían a caballo

${ }^{69}$ Vid. Diago Hernando, «El mercado lanero en la región», págs. 72-73.

${ }^{70}$ En Soria, 28-VII-1616 Francisco López se obligó conjuntamente con Francisco Manuel a pagar al regidor soriano Francisco González de Río 5.198 reales por el valor de 226 arrobas de añinos que le habían comprado a 23 reales la arroba. AHPS, PN, 441-781-235. En otras ocasiones en que Francisco López aparece asociado con Francisco Manuel, el primero es identificado como vecino de Segovia. Un testimonio en AHPS, PN, 220-450-137, Soria, 3-VIII-1610. Deducimos, por tanto, que debió ser vecino de la ciudad del Eresma antes de serlo de Soria. 
entre Portugal, Castilla y Francia, y que, cuando decidieron arraigar en un lugar, optaron finalmente por ciudades francesas u otras de la Corona de Castilla, como Madrid o Valladolid. En claro contraste con ellos, los portugueses que arraigaron en Soria tuvieron escasa participación en el comercio de exportación, o, al menos, ocuparon en el mismo una posición claramente subordinada. Y, aunque ciertamente éstos también dedicaron una parte importante de su actividad al trato con lanas, se centraron de forma preferente en las churras y riberiegas, destinadas a satisfacer la demanda de la manufactura pañera local, que ellos mismos potenciaron en calidad de empresarios-pañeros. Por otro lado, mientras que el origen judeoconverso de la práctica totalidad de los exportadores de lanas portugueses está fuera de duda, en lo que respecta a las familias originarias de Portugal que se asentaron en Soria a finales del reinado de Felipe II se nos plantean más dudas a la hora de determinar si descendían de judíos o no, sobre todo porque, habiendo logrado la plena integración en la sociedad soriana, se esforzaron a lo largo de todo el siglo XVII por resaltar su condición de hidalgos y cristianos viejos. En cualquier caso, no ha sido nuestro objetivo en el presente trabajo profundizar en el análisis del proceso de asentamiento en Soria de estas familias portuguesas, a las que tenemos intención de dedicar un estudio monográfico más adelante, en el que trataremos de poner de manifiesto sus peculiaridades.

\section{CONCLUSIÓN}

La irrupción de los mercaderes portugueses de origen judeconverso en el comercio de exportación de lanas finas de la región soriana a partir de los últimos años del siglo XVI, que muy probablemente tuvo sus equivalentes en otras regiones de la Corona de Castilla productoras de lanas finas para la exportación, aunque hasta el momento no se han emprendido apenas trabajos de investigación para comprobarlo, representa un fenómeno de gran relevancia para la historia económica y social de la Corona de Castilla, sobre el que se ha llamado muy poco la atención en las obras de síntesis. En el presente trabajo hemos tratado de demostrar que se trató de un proceso muy rápido y de efectos contundentes, en el que participaron multitud de individuos que, en líneas generales, no responden al perfil de los grandes financieros portugueses, con intereses en la exportación de lanas, que son los únicos que hasta ahora han despertado el interés de los historiadores del siglo XVII castellano. Por el contrario fueron personajes de modesto origen, y capacidad financiera bastante limitada, pero dotados de un extraordinario espíritu emprendedor 
y sorprendentemente predispuestos a los continuos cambios de residencia y a traspasar una y otra vez las fronteras entre los reinos para sacar adelante sus negocios.

La irrupción de estos portugueses en el comercio de exportación de lanas no tuvo lugar inmediatamente después de que se produjese la quiebra y retirada de las principales casas mercantiles burgalesas, que habían controlado una parte importante del comercio de exportación de lanas finas por los puertos del Cantábrico durante los siglos XV y XVI. Hubo una fase intermedia en que coexistieron exportadores de muy variadas procedencias, aunque la identidad de muchos de ellos todavía está pendiente de clarificación, pues no se han acometido los trabajos de investigación precisos para conocer con más detalle esta etapa del comercio exterior castellano. Pero no cabe duda de que la desaparición de los burgaleses generó un cierto vacío que finalmente los portugueses supieron aprovechar. Queda por explicar por qué no comenzaron a hacerlo antes. Probablemente las trabas a la libre circulación de los judeoconversos por el territorio de la Corona de Castilla que todavía estuvieron vigentes durante el reinado de Felipe II supusieron un importante freno. Pero no hay que descartar que también interviniesen otros factores, que sólo podrán ser identificados mediante análisis en profundidad de la evolución del negocio de producción y exportación de lanas de ganado trashumante en la Corona de Castilla en las tres últimas décadas del siglo XVI, período extraordinariamente complejo en el que se produjo la primera gran crisis que afectó a esta actividad, que hasta entonces había atravesado una etapa extraordinariamente prolongada de prosperidad.

Los factores que propiciaron el fulgurante éxito de los portugueses en la empresa de hacerse con el control del mercado de exportación de lanas finas en la región soriana también resultan difíciles de precisar en el estado actual de las investigaciones. No obstante consideramos que está fuera de duda que algunos de los principales guardan relación con la propia idiosincrasia del grupo mercantil portugués que operó en la región soriana, derivada del hecho de que sus miembros conformaban una minoría social, definida por sus creencias religiosas y costumbres y formas de vida asociadas a las mismas. La práctica totalidad de los mercaderes exportadores de origen portugués que irrumpieron en esta región a fines del siglo XVI fueron, en efecto, judeoconversos. Y su pertenencia a esta minoría, que en muchos aspectos puede considerarse que se encontraba discriminada en las sociedades castellana y portuguesa de los siglos XVI y XVII, explica determinados rasgos de sus formas de vida que resultaron a todas luces propicios para facilitar su éxito en el negocio del comercio exportador. Entre ellos cabría destacar la propensión a la movilidad, con 
la consiguiente dispersión de los miembros de una misma familia por áreas geográficas sumamente extensas, que terminaron por abarcar prácticamente toda Europa Occidental, y el importante papel que desempeñaron en su vida profesional los vínculos del parentesco, sin duda determinantes para la buena marcha de cuantos negocios emprendieron.

Recibido: 08/02/2010

Aceptado: 20/04/2010 